\title{
Cold sensitivity test for individuals with non- freezing cold injury: the effect of prior exercise
}

\author{
Clare M Eglin*, Frank StC Golden and Michael J Tipton
}

\begin{abstract}
Background: One of the chronic symptoms of non-freezing cold injury (NFCl) is cold sensitivity. This study examined the effects of prior exercise on the response to a cold sensitivity test (CST) in NFCI patients with the aim of improving diagnostic accuracy.

Methods: Twenty three participants, previously diagnosed with NFCl by a Cold Injuries Clinic, undertook two CSTs. Participants either rested (air temperature $31^{\circ} \mathrm{C}$ ) for approximately 80 min (prior rest condition (REST)) or rested for 30 min before exercising gently for 12 min (prior exercise condition (EX)). Following REST and EX, the participants placed their injured foot, covered in a plastic bag, into $15^{\circ} \mathrm{C}$ water for $2 \mathrm{~min}$; this was followed by spontaneous rewarming in $31^{\circ} \mathrm{C}$ air for $10 \mathrm{~min}$.
\end{abstract}

Results: The great toe skin temperature $\left(T_{\text {sk }}\right)$ before immersion averaged $32.5(3.4)^{\circ} \mathrm{C}$ in both conditions. Following immersion, the rate of rewarming of the great toe $T_{\text {sk }}$ was faster in EX compared to REST and was higher 5 min $\left(31.7(3.4)^{\circ} \mathrm{C}\right.$ vs. $29.8(3.4)^{\circ} \mathrm{C}$ ) and $10 \mathrm{~min}\left(33.8(4.0)^{\circ} \mathrm{C}\right.$ vs. $\left.32.0(4.0)^{\circ} \mathrm{C}\right)$ post-immersion. Over the first $5 \mathrm{~min}$ of rewarming, changes in the great toe $T_{\text {sk }}$ correlated with the changes in skin blood flow (SkBF) in EX but not the REST condition. No relationship was observed between $T_{\text {sk }}$ in either CST and the severity of NFCI as independently clinically assessed.

Conclusions: Exercise prior to the CST increased the rate of the toe $T_{\text {sk }}$ rewarming, and this correlated with the changes in SkBF. However, the CST cannot be used in isolation in the diagnosis of NFCl, although the EX CST may prove useful in assessing the severity of post-injury cold sensitivity for prognostic and medico-legal purposes.

Keywords: Cold challenge, Blood flow, Skin temperature, Infrared thermography, Laser Doppler, Exercise

\section{Background}

Non-freezing cold injury (NFCI) is caused by prolonged exposure to cold and often wet environments. It is most commonly reported in the feet although the hands can also be affected. NFCI is usually associated with the military where it is the most common form of non-combat related injury in cold/temperate environments [1]. However, it may also occur in civilian populations undertaking recreational outdoor pursuits such as mountaineering and hill walking [2-4], diving [5], cycling [6], or in those working in hostile environments, e.g. fishing industry, agricultural workers, cold storage, etc. [7,8]. There have also been reports of NFCI in homeless individuals [7,9] and the elderly $[10,11]$.

\footnotetext{
* Correspondence: clare.eglin@port.ac.uk

Department of Sport and Exercise Science, Extreme Environments Laboratory, University of Portsmouth, Portsmouth PO1 2ER, UK
}

During World War II, Ungley identified four stages of NFCI in shipwrecked mariners $[12,13]$ : in stage 1, during cold exposure, the tissue is ischaemic and numb; during rewarming (stage 2), the tissue becomes mottled blue and painful. In stage 3 , the hyperaemic stage, which may last for up to 4 weeks, the tissue becomes swollen, red and hot with pain that may be persistent and severe. Stage 4, the chronic state, is characterised by cold sensitivity, numbness, hyperhidrosis and persistent pain that may last for many years. These chronic effects of NFCI may produce debilitating neurological problems including pain, paraesthesia, and even impaired neuromuscular function in severe cases that may have life-changing consequences for the individual. The cold sensitivity, which is an exaggerated vasoconstrictor response (in intensity and duration) to a cold stimulus, alone may cause protracted peripheral vasoconstriction leading to an increase in
C Biomed Central 
peripheral cooling and associated pain and numbness. Such consequences may affect employability status, increase living costs due to the requirement of specialised clothing and increased domestic heating, as well as restrict the individual's participation in normal outdoor sporting or social activities. Cold sensitivity may also increase an individual's risk of further cold injury on exposure to cold. As a consequence, in the military, many individuals diagnosed with NFCI are medically discharged [1]. Therefore, accurate identification of the severity of these long-term symptoms and the efficacy of their treatment is of importance in deciding future employability and treatment regimes in both military and civilian populations.

Cold sensitivity is assessed in cold injury clinics in the UK using a cold challenge test that involves the patient resting in an environment at $30^{\circ} \mathrm{C}$ for an hour before placing their injured limb in a plastic bag (to keep it dry) and immersing it in water at $15^{\circ} \mathrm{C}$ for $2 \mathrm{~min}$. The limb is then allowed to rewarm spontaneously in air for $5 \mathrm{~min}$. The assessment of the severity of the cold sensitivity is based on the skin temperature of the coldest digit measured using infrared thermography before immersion and after 5 min of rewarming $[14,15]$. The underlying principle behind the cold sensitivity test (CST) is that skin temperature reflects changes in local skin blood flow, and with a normal response, the peripheral vasculature will be vasodilated in a warm environment, vasoconstrict on exposure to cold and then quickly vasodilate on removal from the cold. Lower starting skin temperatures and slower rates of skin temperature rewarming indicate an exaggerated vasoconstriction and thus cold sensitivity. The diagnosis of NFCI is based on a combination of this cold sensitivity grading, the threshold of cold sensation measured using a thermal sensitivity tester, as well as a clinical consultation.

Studies in a control group of uninjured individuals have demonstrated that the response to the CST is variable both between and within individuals [16]. The studies indicated that some individuals, although not previously diagnosed with NFCI, may have a degree of cold sensitivity. It also raised questions about the specificity of the CST. The variability within uninjured individuals seen on repeat testing can be reduced by elevating core temperature slightly by performing gentle exercise prior to immersion [14]. This may also improve the sensitivity of the CST by removing any confounding influence of central vasoconstrictor drive, thus leaving the peripheral response to the CST as the primary determinant of the test result. This is desirable since NFCI is a local and not a systemic injury.

Preliminary unpublished pilot data on ten NFCI patients indicated that undertaking gentle exercise prior to the CST resulted in a cold sensitivity grading that was closer to an independent clinical assessment of NFCI [17]. Therefore, the aim of the present study was to expand upon these results using a larger cohort of individuals with NFCI. This study tested the hypothesis that, in comparison with resting in a warm environment, a short period of light exercise prior to undertaking a CST would accelerate the rate of return of skin temperature post-immersion as a result of increased blood flow to the injured extremity. To determine whether the severity of cold sensitivity can be used to diagnose NFCI, the results from both CSTs were compared to an independent clinical assessment of the severity of NFCI.

\section{Methods \\ Participants}

Twenty three individuals (17 African-Caribbean males, 4 Caucasian males, 2 African-Caribbean females, mean (SD) age, 29 (4) years) previously diagnosed with NFCI of the feet or hands and feet by a Cold Injuries Clinic gave their written informed consent to participate. The participants were referred to us as medico-legal cases for independent assessment of their NFCI, and therefore, no information on their original NFCI diagnosis by the Cold Injuries Clinic was available. Each undertook two CSTs of their injured limb (foot or foot and hand), one test in the morning and one in the afternoon. The order of the CSTs was randomized. The participants refrained from caffeine and smoking for $3 \mathrm{~h}$ prior to testing. The assessment was approved by a research ethics committee within the University of Portsmouth and was undertaken between January 2009 and 2011.

\section{Procedure}

On arrival, the participants, wearing trousers and a longsleeved top, entered a waiting room controlled at 31.1 $(0.9)^{\circ} \mathrm{C}$. Having removed their socks and shoes, they sat at rest for an average (SD) of 79 (19) $\mathrm{min}$ in the prior rest condition (REST) and for 31 (11) $\mathrm{min}$ in the prior exercise condition (EX). They then walked $15 \mathrm{~m}$ wearing slippers to another climatic chamber $\left(30.6(0.5)^{\circ} \mathrm{C}\right.$, relative humidity range $36 \%$ to $41 \%$ ). In the REST condition, the participants sat for a further $10 \mathrm{~min}$ prior to the CST. In the EX condition, they performed light to moderate exercise for up to $12 \mathrm{~min}$ prior to the CST. The exercise consisted of either stepping at 22 steps. $\mathrm{min}^{-1}$ on a 20-cm step for 7-10 $\min (n=3)$, exercising on an arm crank ergometer for $12 \mathrm{~min}$ at approximately $10 \mathrm{~W}(n=1)$ or cycle ergometer for $12 \mathrm{~min}$ at $55(20) \mathrm{W}(n=19)$. The mode, intensity and duration of exercise varied between participants due to varying fitness levels and peripheral neural pain experienced on exercising. A previous study in non-cold injured participants found increases in aural temperature of $0.3^{\circ} \mathrm{C}$ with these exercise intensities and ambient conditions [14]. Following the rest or exercise period, the participant sat reclined on a couch, and a multichannel laser Doppler probe (MoorLab System, 
Moor Instruments, Axminster, UK) was affixed using double-sided tape to the pad of the great toe of both feet to measure skin blood flow (SkBF). Two minutes of resting data were collected before commencing the CST.

During the CST, the injured foot was placed in a plastic bag (to keep it dry) and immersed to the level of the midmalleoli for $2 \mathrm{~min}$ in stirred water at $15.0(0.2)^{\circ} \mathrm{C}$. The foot was then taken out of the water, the bag was removed, and the participant remained resting in a recumbent position on a couch for $10 \mathrm{~min}$ to allow spontaneous rewarming. Fourteen participants (ten African-Caribbean males, three Caucasian males and one African-Caribbean female) also had a CST performed on their injured hand (immersion to the level of the wrist) following the CST on their foot. The same procedure as that used with the foot was undertaken, with no further rest or exercise carried out between the tests.

Twenty two of the participants were assessed for NFCI whilst resting in a room at $31^{\circ} \mathrm{C}$ by a clinician with over 30 years experience of NFCI (one participant declined to see the clinician but undertook the two CSTs). The participants were interviewed to ascertain a detailed history including the circumstances leading to their NFCI, a description of the symptoms at the time of injury and the current condition/complaint. A physical examination was conducted to determine the appearance, trophic changes, degree of hyperhidrosis, peripheral pulse, capillary filling, sensation and gait of the injured limb. The severity of NFCI was based on the findings from the history and examination and was derived independently of the results from the CSTs.

\section{Measurements}

Skin temperature $\left(T_{\mathrm{sk}}\right)$ of the toe/finger pads of the immersed foot/hand was measured using a FLIR Systems A320G thermographic camera (UK) pointed at the soles of both feet/palm of both hands. Infra-red images, captured at $1 \mathrm{~Hz}$ to a remote computer, and $T_{\text {sk }}$ were analysed at the following time points: prior to rest/exercise, prior to immersion, and every minute during rewarming. SkBF was recorded throughout the CST in arbitrary laser Doppler units (LDU) and minute averages were calculated for 2 min prior to immersion, during immersion and throughout the rewarming period. A biological zero Doppler measurement was taken on completion of each CST by manually compressing the arterial flow to the great toe/thumb.

As very similar $T_{\text {sk }}$ profiles were observed for toes 2 to 5 , the mean of these $\left(T_{\mathrm{t} 2-5}\right)$ and the $T_{\mathrm{sk}}$ of the great toe $\left(T_{\mathrm{Gt}}\right)$ were analysed. $T_{\mathrm{t} 2-5}$ and $T_{\mathrm{Gt}}$ prior to immersion, at 5 and $10 \mathrm{~min}$ of rewarming and the time taken to rewarm to $63 \%$ of the pre-immersion $T_{\text {sk }}$ (calculated from the following equation $T_{63 \%}=\left[T_{\mathrm{PRE}}-T_{\mathrm{IMM}}\right] 0.63+T_{\mathrm{IMM}}$, where $T_{\mathrm{PRE}}$ is the pre-immersion $T_{\mathrm{sk}}$ and $T_{\mathrm{IMM}}$ is the $T_{\mathrm{sk}}$ immediately after immersion, $[18,19])$ were compared between REST and EX. $T_{\mathrm{sk}}$ of the thumb $\left(T_{\mathrm{th}}\right)$ and the mean $T_{\text {sk }}$ of the fingers $\left(T_{\mathrm{f}}\right)$ were compared between REST and EX prior to immersion and at 5 and $10 \mathrm{~min}$ of rewarming.

\section{Data analyses}

$T_{\text {sk }}$ and SkBF data were analysed using Shapiro-Wilks and Kolmogorov-Smirnov tests of normality. To determine whether there was an order effect, $T_{\mathrm{sk}}$ before immersion and at $5 \mathrm{~min}$ of the first and second CST were compared using either an independent $t$ test or a Mann-Whitney $U$ test. Differences in skin temperature $\left(T_{\mathrm{Gt}}, T_{\mathrm{t} 2-5}, T_{\mathrm{th}}\right.$ and $\left.T_{\mathrm{f}}\right)$ and skin blood flow between REST and EX were analysed using a paired $t$ test or Wilcoxon signed-rank test.

Spearman's rank order correlation was used to investigate relationships between the severity of NFCI of the foot (from physical examination and personal history) and the $T_{\mathrm{sk}}$ obtained during the CSTs before immersion and at 5 and $10 \mathrm{~min}$ of rewarming. The relationship between change in $T_{\mathrm{Gt}}$ and change in SkBF over the first 5 min of rewarming was investigated using Spearman's rank order correlation for EX and a Pearson's product moment correlation for REST. Values are given as the arithmetic mean (standard deviation). Statistical significance was taken at the $5 \%$ level $(P<0.05)$.

\section{Results}

On average, the participants were assessed 4.2 years (range 1 to 9.3 years) after their original injury. Typically, the injury occurred as a result of prolonged ( 5 days to 3 weeks) exposure to cold/freezing and often wet conditions. The severity of NFCI in the feet determined from the participants' personal history and physical examination by the independent clinician was as follows: three uninjured, four mild, six mild/moderate, eight moderate, and one moderate-severe. The severity of NFCI in the hands was as follows: four uninjured, two mild, six mild/moderate, and one moderate.

No differences were found in $T_{\mathrm{Gt}}$ or $T_{\mathrm{t} 2-5}$ between the first and second CST for either REST or EX conditions before immersion or at $5 \mathrm{~min}$, indicating that the order of testing did not influence the $T_{\mathrm{sk}}$ observed.

The $T_{\text {sk }}$ of the toes before and during the REST and EX CST are shown in Figure 1. $T_{\text {sk }}$ before immersion was similar in both conditions (Figure 1) as was the $T_{\text {sk }}$ at $63 \%$ of pre-immersion values $\left(T_{\mathrm{Gt}}\right.$ : REST $28.7(2.5)^{\circ} \mathrm{C}$, EX 29.4 (3.0 $)^{\circ} \mathrm{C} ; T_{\mathrm{t} 2-5}$ : REST $28.0(2.4)^{\circ} \mathrm{C}$, EX $28.1(2.8)^{\circ} \mathrm{C}$, $P>0.05)$. The rate of rewarming of the great toe was faster in EX, with $T_{\mathrm{Gt}}$ reaching $63 \%$ of pre-immersion values sooner than during REST (178 (99) $\mathrm{s}$ vs. 249 (163) $\mathrm{s}, t=$ 2.148, $P=0.048)$. This faster rate of rewarming resulted in higher $T_{\mathrm{Gt}}$ at 5 and $10 \mathrm{~min}$ (Figure 1A). A faster rate of 
A

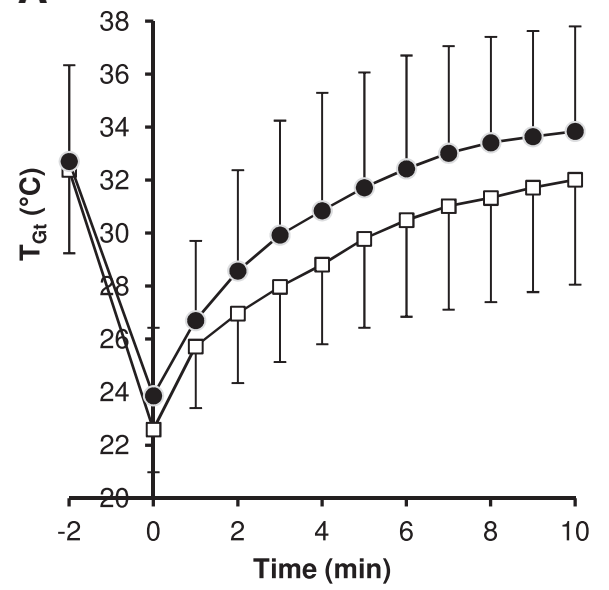

B

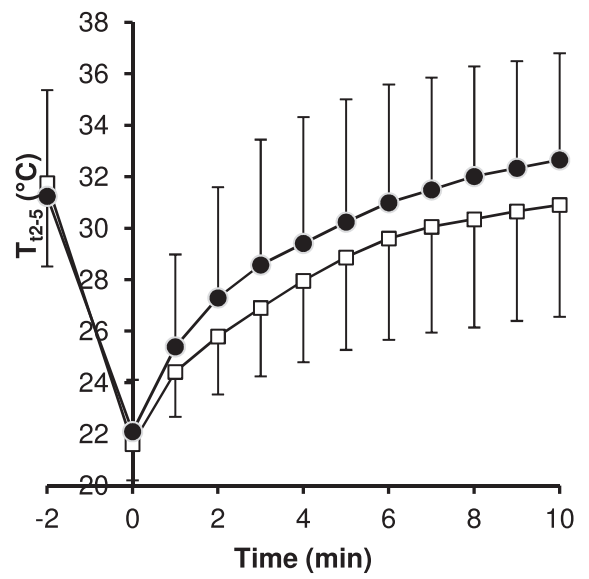

Figure 1 Mean skin temperature (SD) of the toe pads during the REST and EX CSTs. (A) $T_{\text {sk }}$ of the great toe pad $(n=23)$. (B) Average $T_{\text {sk }}$ of toes 2 to $5(n=23)$. REST (open squares) and EX (filled circles).

rewarming during EX was not as apparent in $T_{\mathrm{t} 2-5}$, with only $T_{\mathrm{t} 2-5}$ at $10 \mathrm{~min}$ being greater than REST (Figure 1B).

The cold sensitivity gradings based on the participants' $T_{\text {sk }}$ before immersion and after 5 min rewarming are shown in Figure 2. No significant difference in grades was observed between the REST and EX conditions for either the great toe or the mean of toes $2-5$. There was no relationship between the classification of NFCI made independently by the clinician and the results of the laboratory CST test (Figure 2).

Absolute SkBF in the great toe was higher in the EX condition compared to the REST condition before immersion and during rewarming (Figure 3A). When the SkBF was normalised to the resting pre-immersion levels, no differences were observed between CST at either 5 min (REST 96 (47)\%, EX $110(55) \%, P>0.05)$ or 10 min (REST 141 (68)\%, EX 153 (90)\%, $P>0.05$ ).

The change in $T_{\mathrm{Gt}}$ was correlated with the change in great toe $\mathrm{SkBF}$ over the first $5 \mathrm{~min}$ of rewarming in the EX $(r=0.598, P=0.003)$ but not REST condition (Figure 4).

$T_{\text {sk }}$ of the thumb and fingers before and during the REST and EX CST are shown in Figure 5. No differences were observed between the REST and EX conditions for either $T_{\text {sk }}$ or SkBF (Figures $3 \mathrm{~B}$ and 5). No relationship was observed between the change in $T_{\text {th }}$ and thumb SkBF over the first 5 min of rewarming in either CST.

Based on $T_{\text {sk }}$ of the thumb before immersion and after 5 min rewarming, all but one individual were graded as having a normal response to the CST (however, it was not the same individual for both tests: in the REST condition, one participant was graded as moderate/severe, and in the EX condition, another participant was graded as borderline). Based on the mean $T_{\mathrm{sk}}$ of the fingers, two individuals were graded severe and one as borderline in the REST condition and one as borderline and one as mild-moderate in the EX test; the rest were graded as normal.

\section{Discussion}

The diagnosis of NFCI in patients suffering overt neurological changes is relatively straightforward, but quantifying the degree of residual cold sensitivity from the patient's history alone can be difficult. Yet, for prognostic and medical disposal reasons, an accurate assessment of the degree of sensitivity is important, especially in medico-legal cases. The long-term sequelae of NFCI is very variable with about $60 \%$ of individuals reporting cold sensitivity and $70 \%$ pain [15]. This was supported in the current study by the range in severity of NFCI and cold sensitivity in individuals who were all seeking compensation for their cold injury. In addition, severity of symptoms during and shortly after the original cold exposure does not necessarily predict the long-term symptoms [13].

This study was undertaken to compare two methods of assessing the cold sensitivity of individuals with NFCI in an endeavour to improve the diagnostic capability of the test. It was hypothesised that compared to the REST condition, performing mild exercise before the CST (EX) would remove any residual central vasoconstrictor tone thus increasing the rate of rewarming in the limbs of individuals with mild to moderate cold sensitivity. It was anticipated that this would result in a better correlation with the independent clinical assessment of NFCI, which was based on the symptoms, history and examination.

The EX CST resulted in a faster rate of rewarming and consequently a higher $T_{\text {sk }}$ at 5 and 10 min compared to the REST condition (Figure 1). However, this did not translate into a statistically significant difference in the 


\begin{tabular}{|c|c|c|c|c|c|c|c|c|}
\hline \multirow{4}{*}{$\begin{array}{c}\text { Clinical } \\
\text { NFCI } \\
\text { classification }\end{array}$} & \multicolumn{8}{|c|}{ Laboratory CST } \\
\hline & \multicolumn{4}{|c|}{ Great toe $\mathbf{T}_{\text {sk }}\left({ }^{\circ} \mathbf{C}\right)$} & \multicolumn{4}{|c|}{ Toes 2-5 $\mathrm{T}_{\text {sk }}\left({ }^{\circ} \mathrm{C}\right)$} \\
\hline & \multicolumn{2}{|c|}{ REST } & \multicolumn{2}{|c|}{ EX } & \multicolumn{2}{|c|}{ REST } & \multicolumn{2}{|c|}{$\mathbf{E X}$} \\
\hline & pre & $5 \min$ & pre & $5 \mathrm{~min}$ & pre & $5 \mathrm{~min}$ & pre & $5 \mathrm{~min}$ \\
\hline \multirow[t]{3}{*}{ Normal } & 30.2 & 26.4 & 35.4 & 35.9 & 30.1 & 26.1 & 35.3 & 35.4 \\
\hline & 33.2 & 32.6 & 36.5 & 36.4 & 33.1 & 32.3 & 36.0 & 36.0 \\
\hline & 35.8 & 31.5 & 36.6 & 37.0 & 35.5 & 30.5 & 36.3 & 36.3 \\
\hline \multirow{4}{*}{ Mild } & 34.1 & 33.6 & 32.2 & 29.4 & 33.1 & 29.6 & 30.3 & 27.1 \\
\hline & 29.8 & 26.7 & 36.2 & 34.5 & 28.7 & 25.8 & 32.4 & 28.2 \\
\hline & 33.1 & 27.8 & 31.6 & 27.6 & 31.5 & 26.1 & 27.5 & 24.5 \\
\hline & 31.2 & 26.6 & 26.3 & 24.4 & 31.2 & 25.8 & 26.6 & 24.0 \\
\hline \multirow{6}{*}{$\begin{array}{c}\text { Mild- } \\
\text { moderate }\end{array}$} & 29.5 & 26.3 & 30.9 & 31.4 & 29.3 & 26.7 & 29.3 & 26.7 \\
\hline & 34.5 & 31.1 & 37.3 & 37.2 & 34.4 & 33.1 & 37.3 & 37.2 \\
\hline & 35.8 & 33.0 & 36.1 & 35.9 & 35.6 & 31.8 & 36.4 & 36.7 \\
\hline & 28.0 & 26.6 & 26.6 & 25.7 & 27.6 & 26.3 & 26.6 & 25.3 \\
\hline & 35.2 & 34.4 & 30.4 & 28.8 & 35.6 & 34.5 & 30.5 & 28.9 \\
\hline & 31.0 & 27.9 & 29.0 & 26.0 & 29.6 & 26.6 & 29.0 & 24.8 \\
\hline \multirow{8}{*}{ Moderate } & 32.5 & 28.8 & 29.6 & 34.0 & 31.9 & 28.3 & 31.9 & 33.8 \\
\hline & 25.1 & 25.1 & 26.9 & 26.3 & 25.0 & 25.0 & 26.4 & 26.3 \\
\hline & 33.9 & 32.4 & 29.7 & 33.3 & 34.1 & 30.0 & 29.3 & 29.3 \\
\hline & 25.0 & 23.6 & 29.9 & 27.6 & 24.8 & 22.9 & 31.5 & 26.7 \\
\hline & 35.0 & 34.2 & 37.0 & 37.2 & 35.3 & 34.7 & 37.1 & 37.1 \\
\hline & 35.1 & 32.0 & 34.3 & 30.0 & 34.8 & 33.2 & 34.1 & 30.6 \\
\hline & 33.3 & 29.5 & 35.4 & 32.4 & 31.9 & 28.0 & 35.0 & 31.7 \\
\hline & 35.3 & 35.3 & 36.4 & 36.3 & 34.8 & 34.8 & 36.4 & 36.3 \\
\hline $\begin{array}{l}\text { Moderate- } \\
\text { severe }\end{array}$ & 33.9 & 31.5 & 35.7 & 35.1 & 29.8 & 26.1 & 32.0 & 28.1 \\
\hline
\end{tabular}

Figure 2 Comparison of the skin temperature measured during the CSTs and NFCl severity assessed clinically. The skin temperatures for the great toe and the mean of toes 2-5 for the REST and EX conditions are grouped according to the severity of NFCl clinically determined independently of the CST. Skin temperatures before immersion and that after $5 \mathrm{~min}$ of rewarming are given. The cold sensitivity grading resulting from these skin temperatures [14] are indicated by colours: normal $=$ green, borderline $=$ light green, mild $=$ blue, mild-moderate $=$ pink, moderate $=$ yellow, moderate-severe $=$ orange, severe $=$ red.
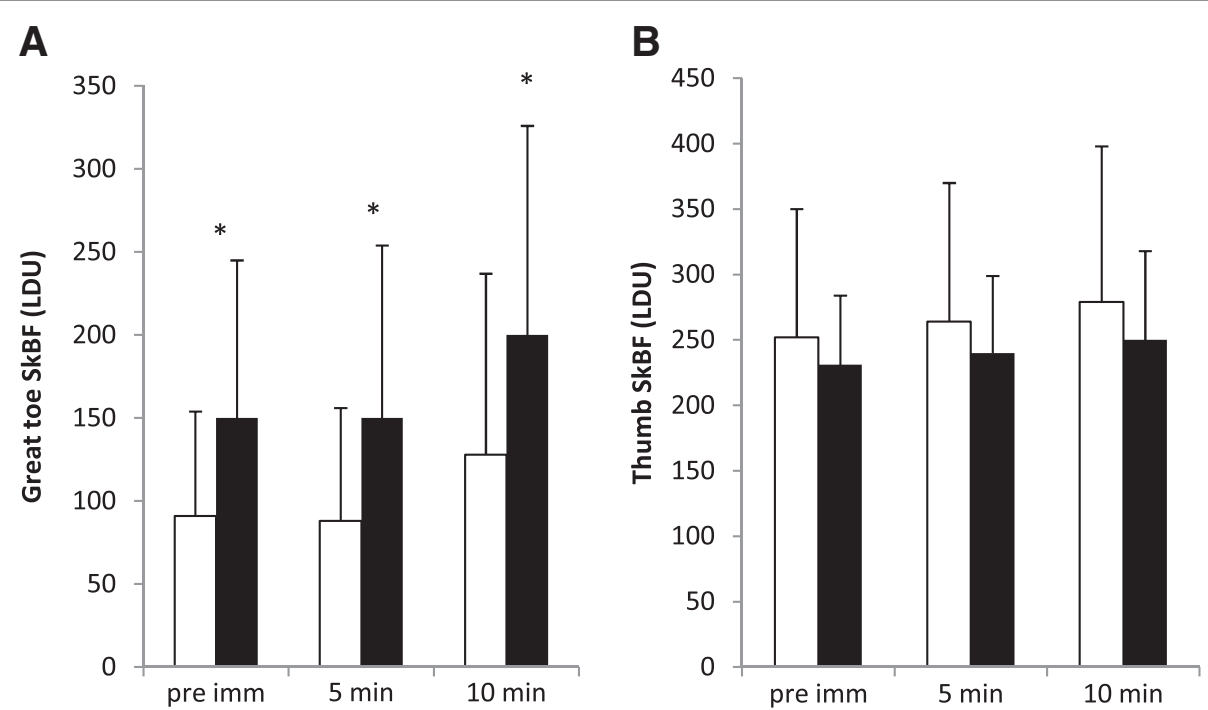

Figure 3 Mean skin blood flow (SD) during the REST and EX CST. Each bar represents the average SkBF over a minute period. REST (open bars) and EX (filled bars). Asterisk indicates a significant difference between REST and EX $(P<0.05)$. (A) Mean SkBF of the great toe pad $(n=23)$. (B) Mean SkBF of the thumb $(n=14)$. 

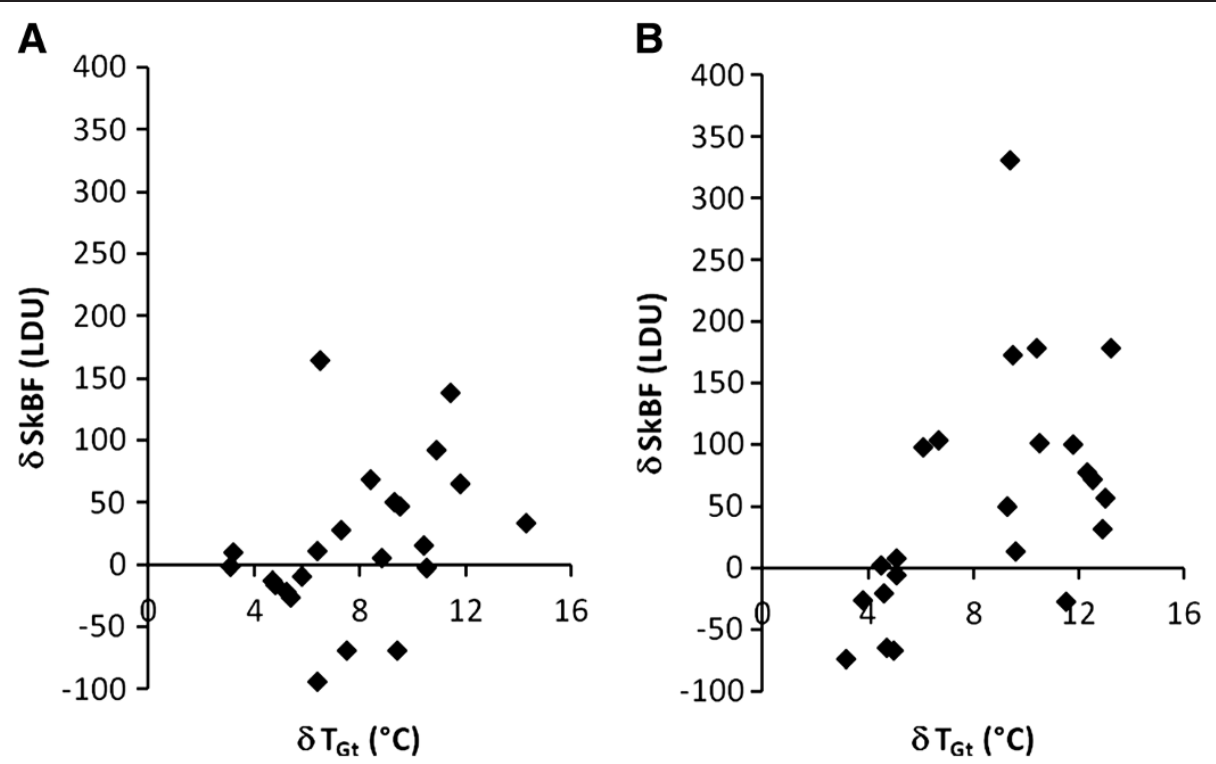

Figure 4 Relationship between the change in great toe skin blood flow and the change in skin temperature. The change was calculated over the first 5 min of rewarming during the REST and EX CST. (A) REST CST $(r=0.368, P=0.84)$. (B) EX CST $(r=0.598, P=0.003)$.

cold sensitivity grading between the two CST. This was due to the strong effect of the starting $T_{\text {sk }}$ on the classification given; a $T_{\text {sk }}$ above $32^{\circ} \mathrm{C}$ is classified as normal to mild/moderate, whereas a starting $T_{\text {sk }}$ below $32^{\circ} \mathrm{C}$ is, at best, graded as moderately cold sensitive [14]. Since no difference in starting $T_{\mathrm{sk}}$ was observed between the CSTs (Figure 1), it is not surprising that the derived cold sensitivity gradings were similar. This would suggest that the pre-test skin temperatures observed after equilibration in an ambient temperature of $30^{\circ} \mathrm{C}$ do not accurately reflect the ability of the local tissue temperatures to recover following the cold exposure.

Previous unpublished studies have failed to identify a relationship between skin temperature and blood flow during a CST $[14,17]$. This raised issues regarding the specificity of the CST, as it would be expected that changes in skin temperature would be a result of changes in skin blood flow. It has been hypothesised that this lack of relationship may be due to the presence of a variable degree of central vasoconstrictor tone [14]. In the current study, a moderate relationship $(r=0.598)$ was found between the change in SkBF and $T_{\mathrm{Gt}}$ during the first 5 min of rewarming in the EX but not the REST condition (Figure 4). This suggests that a slight elevation of core temperature through gentle exercise removes this variable central vasoconstrictor tone, thus isolating the peripheral response to the local cold challenge. This should be regarded as a benefit, given that the test should be solely evaluating the effect of a cold stimulus on the local circulatory response in a region with a local

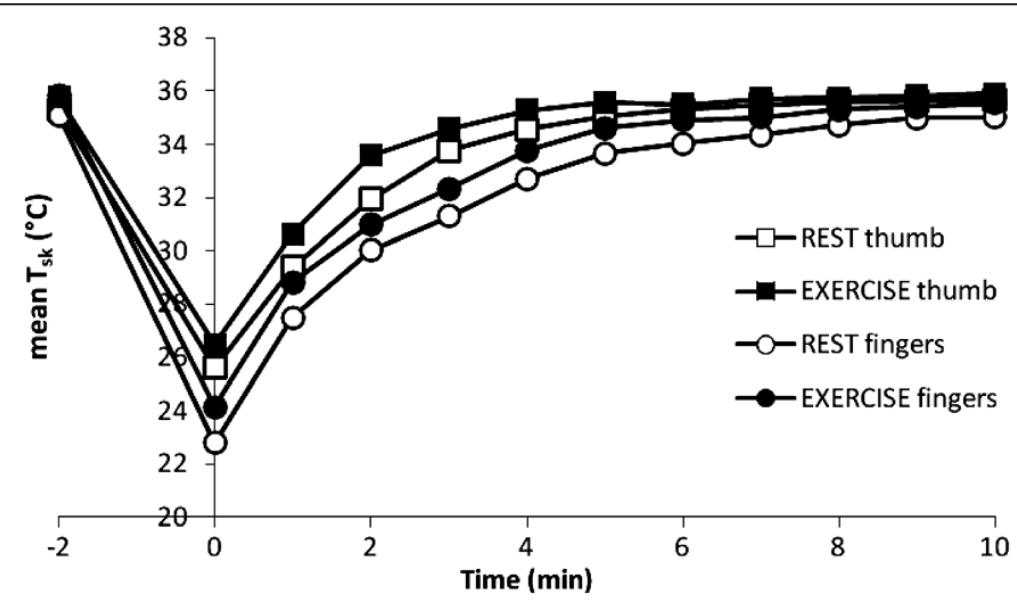

Figure 5 Average mean skin temperature of the thumb and finger pads during the REST and EX CSTs $(n=14)$. 
injury. However, no correlation was found between the severity of NFCI as assessed through the personal history and clinical examination and the skin temperature during either CST (Figure 2). The NFCI clinical diagnosis is based on the detailed history of the original injury (i.e. presence/absence of swelling, blistering or loss of nails) and current condition (e.g. pain, peripheral thermal perception at normal room temperature, trophic changes and any gait problems).

The majority of our participants were of AfricanCaribbean origin and reflect the increased prevalence of NFCI reported in this ethnic group compared to Caucasians in both the British [20] and the US army [21]. The reason for this increased risk of NFCI in African-Caribbeans is unclear. However, there do appear to be ethnical differences in the uninjured response to a cold challenge, with African-Caribbeans showing lower finger $T_{\mathrm{sk}}$ and fewer cold-induced vasodilatations (CIVDs) compared to their Caucasian counterparts [22-24]. The occurrence of CIVDs during a cold challenge when the body is normothermic is thought to provide protection against profound peripheral cooling and thus reduce the risk of cold injuries [25]. Indeed, it has been proposed that repeated cold water immersions of the extremities results in a local cold adaptation characterised by a higher $T_{\mathrm{sk}}$, more CIVDs and less pain which maintains manual performance as well as reducing the risk of NFCI [26]. Therefore, a more pronounced and prolonged vasoconstriction with fewer CIVDs during a cold challenge may make African-Caribbeans more susceptible to NFCI. A comparison between the responses of the African-Caribbean and Caucasian participants (and similarly between males and females) was not possible in the current study due to the varying circumstances and time since their initial injury and the range in severity of the subsequent NFCI.

\section{Conclusions}

It is concluded that gentle exercise prior to undertaking a CST results in a faster rate of $T_{\mathrm{sk}}$ rewarming and shows a better relationship between the $\mathrm{SkBF}$ and $T_{\mathrm{sk}}$ in individuals previously diagnosed with NFCI. Thus, the EX CST may be a useful tool for identifying cold sensitivity. The $T_{\text {sk }}$ measured during either CST did not correlate with the severity of NFCI assessed clinically, and therefore, a cold sensitivity test should not be used, in isolation, to diagnose NFCI.

\footnotetext{
Abbreviations

CST: Cold sensitivity test; EX: Prior exercise condition; LDU: Laser Doppler units; NFCl: Non-freezing cold injury; REST: Prior rest condition; SkBF: Skin blood flow; $T_{f}$ : Finger skin temperature; $T_{\mathrm{Gt}}$ : Great toe skin temperature; $T_{\text {sk }}$ : Skin temperature; $T_{\mathrm{t} 2-5}$ : Mean skin temperature of toes 2 to $5 ; T_{\mathrm{th}}$ : Thumb skin temperature; $T_{63 \%}$ : Time taken to rewarm to $63 \%$ of the pre-immersion $T_{\text {sk }}$.
}

\section{Competing interests}

The authors declare that they have no competing interests.

\section{Authors' contributions}

All the authors contributed to the design of the study and writing the protocol. MT initiated the project and provided funding. FG undertook the clinical assessments, and CE was responsible for the data collection during the CST and analysis of the data. All authors contributed to the writing of the paper and read and approved the final manuscript.

\section{Acknowledgements}

We would like to thank the participants, Martha Davey and Geoff Long, for their technical assistance.

Received: 23 November 2012 Accepted: 22 February 2013

Published: 1 May 2013

\section{References}

1. Oakley EH: The hidden enemy: non-freezing cold injury since the Falklands Conflict. In Proceedings of the NATO, TRO, HFM-168 Symposium on "Soldiers in Cold Environment": 20-22 April 2009. NATO, TRO: Helsinki, Finland; 2009. KN2-1-7.

2. Imray C, Grieve A, Dhillon S: Cold damage to the extremities: frostbite and non-freezing cold injuries. Postgrad Med J 2009, 85:481-488.

3. Imray $\mathrm{CH}$, Oakley EH: Cold still kills: cold-related illnesses in military practice freezing and non-freezing cold injury. J R Army Med Corps 2005, 151:218-222.

4. Marcus P: "Trench foot" caused by the cold. Br Med J 1979, 1(6163):622.

5. Laden GD, Purdy G, O'Rielly G: Cold injury to a diver's hand after a 90-min dive in 6 degrees C water. Aviat Space Environ Med 2007, 78:523-525.

6. Fraser IC, Loftus JA: "Trench foot" caused by the cold. Br Med J 1979, 1(6169):1017.

7. Cattermole TJ: The epidemiology of cold injury in Antarctica. Aviat Space Environ Med 1999, 70:135-140.

8. Mills WJ Jr, Mills WJ 3rd: Peripheral non-freezing cold injury: immersion injury. Alaska Med 1993, 35:117-128.

9. King RC, Parrish JA, Allibone A: Trench-foot in peacetime England. Br Med J 1958, 1(5079):1099-1102.

10. Ramstead KD, Hughes RG, Webb AJ: Recent cases of trench foot. Postgrad Med J 1980, 56:879-883.

11. Williams GL, Morgan AE, Harvey JS: Trench foot following a collapse: assessment of the feet is essential in the elderly. Age Ageing 2005, 34:651-652.

12. Ungley CC, Blackwood W: Peripheral vasoneuropathy after chilling "immersion foot and immersion hand". Lancet 1942, 2:447-451.

13. Ungley CC, Channell GD, Richards RL: The immersion foot syndrome. 1946. Wilderness Environ Med 2003, 14:135-141.

14. Eglin CM, Golden FS, Tipton MJ: Increasing the reproducibility of a cold sensitivity test for non-freezing cold injury. In Proceedings of the 11th International Conference on Environmental Ergonomics: 22-26 May 2005. Edited by Holmer I, Kuklane K, Gao C. Lund: Lund University; 2005:274-277.

15. Thomas JR, Oakley EH: Nonfreezing cold injury. In Medical Aspects of Harsh Environments. Edited by Pandolf KB, Burr RE. Virginia: Office of the Surgeon General, US Army; 2001:467-490.

16. Golden F, Eglin C, Laight D, Tipton M: Non-Freezing Cold Injury: Its Nature and Assessment. Report. Portsmouth: University of Portsmouth, Department of Sport and Exercise Science; 2003.

17. Eglin C, Golden FS, Tipton MJ: Classification of non-freezing cold injury in patients: an interim report. In Proceedings of the 13th International Conference on Environmental Ergonomics: 2-7 August 2009; Boston. Edited by Castellani JW, Endrusick TL. Australia: University of Wollongong; 2009:172176. Proceedings of the 13th International Conference on Environmental Ergonomics: 2-7 August 2009.

18. Foerster J, Kuerth A, Niederstrasser E, Krautwald E, Pauli R, Paulat R, Eweleit M, Riemekasten G, Worm M: A cold-response index for the assessment of Raynaud's phenomenon. J Dermatol Sci 2007, 45:113-120.

19. Foerster J, Wittstock S, Fleischanderl S, Storch A, Riemekasten G, Hochmuth $\mathrm{O}$, Meffert B, Meffert H, Worm M: Infrared-monitored cold response in the assessment of Raynaud's phenomenon. Clin Exp Dermatol 2006, 31:6-12.

20. Burgess JE, Macfarlane F: Retrospective analysis of the ethnic origins of male British army soldiers with peripheral cold weather injury. J R Army Med Corps 2009, 155:11-15. 
21. DeGroot DW, Castellani JW, Williams JO, Amoroso PJ: Epidemiology of U.S. Army cold weather injuries, 1980-1999. Aviat Space Environ Med 2003, 74:564-570

22. lampietro PF, Goldman RF, Buskirk ER, Bass DE: Response of Negro and white males to cold. J Appl Physiol 1959, 14:798-800.

23. Jackson RL, Roberts DE, Cote RA, McNeal P, Fay JT, Sharp MW, Kraus E, Rahman SA, Hamlet MP: Psychological and Physiological Responses of Blacks and Caucasians to Hand Cooling. Report No: T20-89. Natick: US Army Research Institute of Environmental Medicine; 1989.

24. Rennie D, Adams T: Comparative thermoregulatory responses of Negroes and white persons to acute cold stress. J Appl Physiol 1957, 11:201-204.

25. Daanen HA: Finger cold-induced vasodilation: a review. Eur J Appl Physiol 2003, 89:411-426

26. Launay JC, Savourey G: Cold adaptations. Ind Health 2009, 47:221-227.

doi:10.1186/2046-7648-2-16

Cite this article as: Eglin et al:: Cold sensitivity test for individuals with non-freezing cold injury: the effect of prior exercise. Extreme Physiology \& Medicine 2013 2:16

\section{Submit your next manuscript to BioMed Central and take full advantage of:}

- Convenient online submission

- Thorough peer review

- No space constraints or color figure charges

- Immediate publication on acceptance

- Inclusion in PubMed, CAS, Scopus and Google Scholar

- Research which is freely available for redistribution 